\title{
JM
}

Volume 7 No. 2 (Oktober 2019)

(C) The Author(s)

\section{PENGARUH TERAPI AKUPUNKTUR PADA TITIK LI-4 DAN SP-6 TERHADAP NYERI PERSALINAN KALA I FASE AKTIF}

\author{
INFLUENCE OF LI-4 AND SP-6 ACUPUNCTURE POINT TREATMENTS \\ TOWARD STAGE I ACTIVE LABOR PAIN
}

\author{
NOVIANTI \\ PRODI D3 KEBIDANAN FAKULTAS MIPA UNIVERSITAS BENGKULU \\ Email: novianti@unib.ac.id
}

\begin{abstract}
ABSTRAK
Nyeri persalinan merupakan suatu rangsangan nyeri yang terjadi akibat adanya kontraksi uterus selama menjalani proses persalinan. Nyeri persalinan menimbulkan hiperventilasi sehingga kebutuhan oksigen meningkat, kenaikan tekanan darah, dan berkurangnya motilitas usus serta vesika urinaria, dan merangsang peningkatan katekolamin yang dapat menyebabkan gangguan pada kekuatan kontraksi uterus. Salah satu menurunkan nyeri persalinan dapat dilakukan dengan terapi akupunktur titik LI-4 dan SP-6. Penelitian ini bertujuan menganalisis pengaruh terapi akupunktur pada titik LI-4 dan SP-6 terhadap nyeri persalinan kala I fase aktif pada ibu bersalin multigravida. Penelitian ini bersifat quasi eksperimental dengan jumlah sampel 45 ibu bersalin multigravida kala I fase aktif di Puskesmas Garuda Kota Bandung dengan teknik pengambilan sampel konsekutif sampling dibagi dua kelompok secara acak, kelompok perlakuan(P) berjumlah 21 dan kelompok kontrol(K) berjumlah 24. Penilaian skor nyeri menggunakan Visual Analogue Scale (VAS). Pengujian statistik menggunakan analisis non parametrik (uji Wilcoxon) untuk melihat perbedaan nyeri antara pretest dengan posttest, uji Mann-Whitney untuk melihat perbedaan nyeri kedua kelompok penelitian, dan uji Chi-Square untuk melihat hubungan kedua kelompok penelitian dengan kemaknaan hasil uji ditentukan berdasarkan nilai $\mathrm{p}<0,05$. Hasil penelitian menunjukkan nilai pretest tidak terdapat perbedaan antara kelompok $\mathrm{P}$ dan $\mathrm{K}$, nilai posttest skor nyeri rata-rata kelompok $\mathrm{P}$ tidak terdapat peningkatan nyeri sedangkan kelompok $\mathrm{K}$ terdapat peningkatan nyeri pada menit 30, 60, 120, 180, 240 dan 300. Perbedaan nyeri pada kedua kelompok pada menit 60, 120, 180, 240, 300 dan 360. Prosentase peningkatan nyeri pada kelompok K lebih besar dibandingkan dengan kelompok P. Simpulan penelitian ini adalah terapi akupunktur pada titik LI-4 dan SP-6 dapat menghambat peningkatan nyeri persalinan kala I fase aktif dibandingkan dengan kelompok K.
\end{abstract}

\section{Kata Kunci: Akupunktur, titik LI-4, titik SP-6, Nyeri Persalinan}

\begin{abstract}
Labor pain is considered as stimulation of pain caused by uterus contraction during the labor. Labor pain causes hyperventilation leading to several impacts, such as increased oxygen necessity, high blood pressure, and decreased intestine and vesica urinaria motility. It also stimulates the increase of catecholamine causing uterus contraction strength disturbance. However, acupuncture can be performed to reduce labor pain in distinctive acupuncture points,
\end{abstract}


including LI-4 and SP-6 points. This study aimed to analyze the influence of acupuncture therapy at the LI-4 and SP-6 points towards stage I pain in active labor.This was an experimental quasi study included 45 multigravida stage I in active pregnant mothers who visited Garuda Community Health Center, Bandung, Indonesia. The sampling technique used in the study was consecutive sampling. The samples were divided into two groups, 21 pregnant mothers in treatment group (T) and 24 pregnant mothers in control group (C). The labor pain was measured using Visual Analogue Scale (VAS). The study used nonparametric statistical test (Wilcoxon test) to observe different level of pain between pretest and posttest period. This was performed to compare the labor pain in the treatment and control groups with $p$ value $<0.05$. The results showed average value of pain between the $\mathrm{T}$ and $\mathrm{C}$ group in several intervals during the labor: there were not pretest difference value between $\mathrm{T}$ and $\mathrm{C}$. The average value in the $\mathrm{T}$ group meant the samples did not experience significant pain while the $\mathrm{C}$ group experienced significant pain in minute-30, 60, 120, 180, 240, and 300. The percentage of gradual pain in the $\mathrm{C}$ group was higher than the $\mathrm{T}$ group. This study concludes that acupuncture at the LI-4 and SP6 points does not cause stage I pain in active labor and can prevent the gradual labor pain along as compared to the group of $\mathrm{C}$.

\section{Keywords: LI-4 and SP-6 acupuncture points, labor pain}

\section{PENDAHULUAN}

Nyeri persalinan ditimbulkan oleh kontraksi uterus dan pembukaan serviks, secara fisiologis nyeri persalinan semakin lama semakin kuat seiring dengan penambahan pembukaan serviks dan peningkatan kontraksi Rahim. Nyeri persalinan dapat menimbulkan kecemasan pada pasien, menyebabkan timbulnya hiperventilasi sehingga kebutuhan oksigen meningkat, kenaikan tekanan darah, dan berkurangnya motilitas usus serta vesika urinaria. Keadaan ini akan merangsang peningkatan katekolamin yang dapat menyebabkan gangguan pada kekuatan kontraksi uterus sehingga terjadi inersia uteri apabila tidak diatasi, yang akan menyebabkan terjadinya partus lama (Cunningham, 2013: Chapman, 2013)

Metode penatalaksanaan nyeri persalinan yaitu metode farmakologis dan metode non farmakologis. Metode farmakologis merupakan metode penghilang nyeri yang efektif mengurangi nyeri persalinan. Metode farmakologis hanya boleh diberikan oleh dokter berdasarkan kewenangan dan standar kompetensi, karena metode farmakologis membutuhkan prosedur yang memerlukan ketelitian dan kecermatan dalam pemberiannya karena efek samping yang memungkinkan akan berakibat kurang baik untuk ibu dan bayi seperti mual, muntah, memperpanjang lama persalinan, depresi pernafasan dan letargi (Burham, 2003; Anderson, 2011; Fyneface-Ogan, 2012; Gizzo $\mathrm{S}, 2012$ )

Metode non farmakologis meskipun dari efek terapi terdapat pengurangan nyeri tidak sekuat secara farmakologis, tetapi metode non farmakologis memberikan keuntungan selain mengontrol nyeri secara adekuat, tetapi juga memberikan pendekatan secara psikologis jika dilakukan dengan benar dan dapat dilakukan oleh bidan karena berdasarkan wewenang dan standar kompetensi bidan boleh memberikan penatalaksanaan nyeri persalinan dengan metode non farmakologis. Salah satu metode non farmakologis adalah akupunktur, akupunktur merupakan pengobatan tradisional Cina dengan menerapkan keterkaitan antara tubuh, pikiran, dan jiwa (Kiswojo, 2013; Wignyomartono SS; Saputra $\mathrm{K}$, 2009). Konsep dasar dari akupunktur adalah dengan melakukan insersi jarum ke titik tertentu di tubuh (akupoin). Rangsangan titik akupuntur dapat menimbulkan sekresi endogeneus morphine-like substance yang disebut endorfin, yang bekerja pada reseptor 
opiat di susunan saraf pusat dan menghambat transmisi signal nyeri (Kiswojo, 2013; Saputra K, 2009). Penelitian sebelumnya pada titik LI-4 dan SP-6 pada primigravida bahwa akupunktur dapat menghambat nyeri persalinan ( $\mathrm{Qu} \mathrm{F}$, 2006). sedangkan pada penelitian ini menggunakan titik akupunktur yang sama untuk menghambat nyeri persalinan pada ibu bersalin multigravida.

\section{METODE PENELITIAN}

Penelitian ini quasi eksperimental dengan desain Pretest Postest Control Group Design. Jumlah sampel dalam penelitian ini adalah 45 ibu bersalin multigravida kala I fase aktif di Puskesmas Garuda Kota Bandung dengan teknik pengambilan sampel konsekutif sampling dibagi dua kelompok secara acak, kelompok $\mathrm{P}$ berjumlah 21 dan kelompok K berjumlah 24. Kriteria inklusi multigravida inpartu kala I fase aktif (pembukaan $\geq 3-\leq 10 \mathrm{~cm}$ ), aterm dengan kehamilan tunggal, presentasi kepala, kehamilan 37-42 minggu, rencana melahirkan normal, ketuban masih utuh, kontraksi uterus baik, tidak mendapatkan obat atau ramuan lain yang mempunyai efek anti nyeri, mempunyai riwayat persalinan sebelumnya normal dan bersedia menjadi subyek penelitian. Kriteria eksklusi: terdapat disproporsi kepala panggul, kehamilan dengan komplikasi. Kriteria drop out ibu bersalin yang tidak bisa menahan nyeri persalinan dan ibu bersalin yang tidak bisa dilanjutkan persalinan secara pervaginam.

Penilaian nyeri menggunakan Visual Analogue Scale (VAS) dan dinilai oleh bidan observer. Pengukuran VAS pada kedua kelompok dilakukan pada saat his dan pengukuran dilakukan sebelum dilakukan tindakan penatalaksanaan nyeri dan setelah tindakan pada menit $30,60,120,180,240$, 300 dan 360. Hasil pada kedua kelompok dibandingkan antara pretest dan posttest. Analisis data menggunakan uji chi kuadrat, Uji Mann Whitney, dan uji Wilcoxon.

\section{HASIL PENELITIAN}

Semua subjek penelitian ini mengikuti

Tabel 1. Karakteristik Subjek Penelitian Pada Kedua Kelompok Penelitian

\begin{tabular}{|c|c|c|c|}
\hline & \multicolumn{2}{|c|}{ Kelompok } & \multirow[b]{2}{*}{ Nilai p } \\
\hline & $\begin{array}{l}\text { Perlakuan } \\
n=21\end{array}$ & $\begin{array}{c}\text { Kontrol } \\
\mathrm{n}=\mathbf{2 4}\end{array}$ & \\
\hline 1.Usia (Th) & & & $0,032^{* * *}$ \\
\hline$<25$ & 2 & 8 & \\
\hline $25-34$ & 11 & 12 & \\
\hline$\geq 35$ & 8 & 4 & \\
\hline Rerata (SD) & $32,10(5,28)$ & $28,58(5,99)$ & \\
\hline Median & 32 & 29,5 & \\
\hline Rentang & $23-40$ & $17-40$ & \\
\hline 2. Pendidikan & & & $0,905^{*}$ \\
\hline Rendah & 11 & 13 & \\
\hline 3.Pekerjan & & & $1,000^{* *}$ \\
\hline $\begin{array}{c}\text { Tidak } \\
\text { Bekerja }\end{array}$ & 17 & 19 & \\
\hline Bekerja & 4 & 5 & \\
\hline 4.Paritas & & & $0,566^{* * *}$ \\
\hline 2 & 15 & 15 & \\
\hline 3 & 3 & 5 & \\
\hline 4 & 3 & 4 & \\
\hline $\begin{array}{c}5 . \\
\text { Pembukaan } \\
(\mathrm{cm})\end{array}$ & & & $0,231^{*}$ \\
\hline $4-7$ & 18 & 17 & \\
\hline $7-9$ & 3 & 7 & \\
\hline $\begin{array}{c}\text { 6. Berat Bayi } \\
\text { Lahir }(\mathrm{g})\end{array}$ & & & $0,031^{* * *}$ \\
\hline$<2500$ & 1 & 2 & \\
\hline $2500-2999$ & 5 & 13 & \\
\hline$\geq 3000$ & 15 & 9 & \\
\hline Rerata (SD) & $\begin{array}{l}3067,62 \\
(282,45) \\
\end{array}$ & $\begin{array}{l}2894,58 \\
(373,62) \\
\end{array}$ & \\
\hline Median & 3100 & 2900 & \\
\hline Rentang & $2300-3500$ & $1850-3600$ & \\
\hline $\begin{array}{c}\text { 7.Skor Nyeri } \\
\text { Pretest }\end{array}$ & & & $0,112^{* * *}$ \\
\hline Rerata(SD) & $6,05(0,92)$ & $6,13(0,85)$ & \\
\hline $\begin{array}{l}\text { Median(Rent } \\
\text { ang) }\end{array}$ & $6(5-9)$ & $6(4-6)$ & \\
\hline
\end{tabular}

Uji Chi-Square pada taraf signifikansi $5 \%$, **Uji Exact-Fisher pada taraf signifikansi 5\%, ***Uji Mann-Whitney pada taraf signifikansi 5\%

Karakteristik subjek penelitian pada 
kedua kelompok penelitian tampak terdapat perbedaan usia yang bermakna, pada kelompok $\mathrm{K}$ usia $<25$ tahun lebih banyak dibandingkan kelompok P. Pada berat bayi lahir terdapat perbedaan bermakna pada kedua kelompok, berat bayi lahir $\geq 3000 \mathrm{~g}$ lebih banyak pada kelompok $\mathrm{P}$ dibandingkan kelompok.

Tabel 2. Perbedaan Tingkat Nyeri Pada Kedua Kelompok Penelitian

\begin{tabular}{|c|c|c|c|}
\hline \multirow[t]{2}{*}{ Nyeri } & \multicolumn{2}{|c|}{ Kelompok } & \multirow[t]{2}{*}{ Nilai p } \\
\hline & Perlakuan & Kontrol & \\
\hline \multicolumn{4}{|l|}{ Menit 30} \\
\hline Tidak Meningkat & 20 & 13 & $0,01 *$ \\
\hline Meningkat & 1 & 11 & \\
\hline \multicolumn{4}{|l|}{ Menit 60} \\
\hline Tidak Meningkat & 21 & 10 & $0,01 *$ \\
\hline Meningkat & 0 & 11 & \\
\hline \multicolumn{4}{|l|}{ Menit 120} \\
\hline Tidak Meningkat & 13 & 5 & $0,01 *$ \\
\hline Meningkat & 1 & 13 & \\
\hline \multicolumn{4}{|l|}{ Menit 180} \\
\hline Tidak Meningkat & 11 & 2 & $0,01 * *$ \\
\hline Meningkat & 1 & 9 & \\
\hline \multicolumn{4}{|l|}{ Menit 240} \\
\hline Tidak Meningkat & 10 & 5 & $0,033 * *$ \\
\hline Meningkat & 0 & 4 & \\
\hline \multicolumn{4}{|l|}{ Menit 300} \\
\hline Tidak Meningkat & 7 & 2 & $0,045^{* *}$ \\
\hline Meningkat & 0 & 3 & \\
\hline \multicolumn{4}{|l|}{ Menit 360} \\
\hline Tidak Meningkat & 5 & 3 & \\
\hline Meningkat & 0 & 0 & \\
\hline
\end{tabular}

Uji Chi-Square pada taraf signifikansi $5 \%, \quad * *$ Uji Exact-Fisher pada taraf signifikansi $5 \%$

Pada tabel 2 tampak bahwa prosentase peningkatan nyeri pada kelompok Kl lebih besar dibandingkan kelompok P.

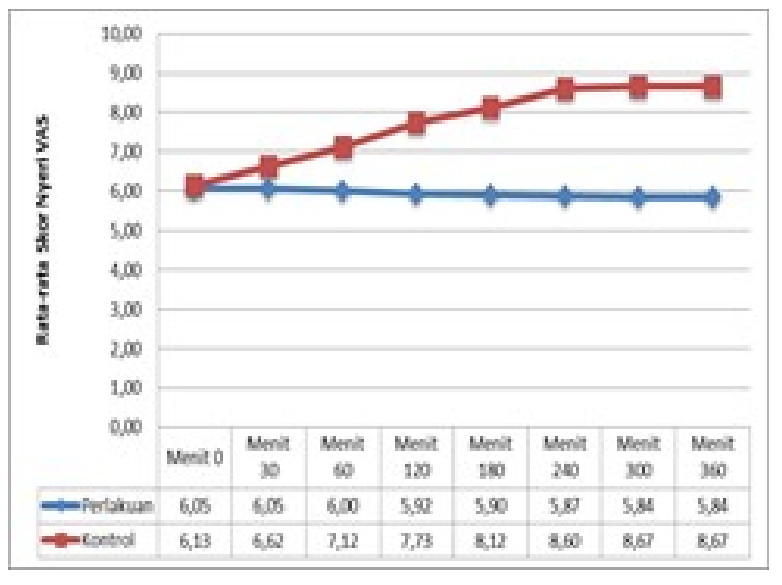

Gambar 1. Perbedaan Skor Nyeri VAS Rata-rata Berdasarkan Waktu Pada Kedua Kelompok Penelitian.

Gambar 1 memperlihatkan perbedaan tingkat nyeri pada kedua kelompok. Pada kelompok $\mathrm{P}$ tidak terjadi peningkatan nyeri sedangkan kelompok $\mathrm{K}$ terjadi peningkatan nyeri.

\section{PEMBAHASAN}

Data karateristik subjek yang tidak menunjukkan secara bermakna dalam pendidikan, pekerjaan, jumlah kehamilan, pembukaan pada saat datang, sedangkan usia dan berat bayi lahir memengaruhi nyeri persalinan, setelah dilakukan uji regresi logistik tidak terdapat pengaruh usia dan berat bayi lahir terhadap nyeri persalinan. Sebelum dilakukan perlakuan pada kedua kelompok, hasil pengujian statistik menggunakan uji Mann-Whitney, diketahui tidak terdapat perbedaan derajat nyeri yang signifikan antara kelompok $\mathrm{P}$ dengan kelompok K. Setelah dilakukan perlakuan pada kedua kelompok penelitian terdapat perbedaan tingkat nyeri bemakna.

Pada kelompok $\mathrm{P}$, hasil pengujian statistik menggunakan uji Wilcoxon, diketahui tidak terdapat perbedaan skala nyeri VAS antara pretest dan postest, tetapi skala nyeri VAS rata-rata menetap seiring dengan waktu. Keadaan ini menandakan bahwa terapi akupunktur pada titik LI-4 dan SP-6 dapat menghambat peningkatan nyeri persalinan. Peningkatan nyeri persalinan dapat dihambat 
walaupun terjadi penambahan pembukaan dan peningkatan his ibu, hal ini sejalan dengan penelitian Ma W dkk di Cina (2011) melakukan penelitian pada $350 \mathrm{ibu}$ bersalin yang dibagi menjadi tiga kelompok yaitu kelompok elektro akupunktur pada titik SP-6, kelompok sham akupunktur dan kelompok kontrol dengan penilaian skor nyeri menggunakan VAS dan hasilnya terdapat penurunan nyeri pada 30 menit, 2 dan 4 jam setelah dilakukan terapi elektro akupunktur pada titik SP-6 (Ma W, 2011)

Penelitian Asadi N dkk di iran (2015) melakukan penelitian pada 63 ibu bersalin yang dibagi menjadi dua kelompok yaitu kelompok akupunktur pada titik LI-4 dan SP6, dan kelompok sham akupunktur, hasil penelitian terdapat perbedaan penurunan nyeri dengan rata-rata nyeri pada kelompok akupunktur sebelum dilakukan intervensi 7,6, setelah dilakukan intervensi menjadi 5,1. Rata-rata nyeri kelompok sham akupunktur sebelum dilakukan intervensi 7,3, setelah dilakukan intervensi 4,9. Kadar kortisol kedua kelompok tidak ada perbedaan antara sebelum dan sesudah intervensi. Kala I fase aktif lebih pendek pada kelompok akupunktur dibandingkan kelompok sham akupunktur. Mucuk S dan Baser M di Turki (2014) meneliti $120 \mathrm{ibu}$ bersalin kala I fase aktif dibagi tiga kelompok yaitu kelompok akupunktur titik LI-4, kelompok akupunktur titik SP-6, dan kelompok kontrol. Hasil penelitian pada kedua kelompok akupunktur dapat menurunkan nyeri dan mempercepat kala I fase aktif dibandingkan kelompok control (Asadi N, 2015).

Pada kelompok $\mathrm{K}$ terjadi peningkatan rasa nyeri dari pretest ke posttest, hal ini terlihat dari hasil uji statistik menggunakan uji Wilcoxon, diketahui bahwa peningkatan tingkat nyeri pada menit 30 , menit 60 , menit 120 , menit 180 , menit 240 dan menit 300 tersebut signifikan. Keadaan ini sesuai dengan teori bahwa secara fisiologis ibu akan mengalami nyeri yang makin lama makin kuat seiring dengan penambahan pembukaan serviks. Tidak jarang ibu yang di akhir kala I persalinan akan berada pada skala nyeri berat atau hebat (Cunningham, 2013; Chapman, 2013; Lowe NK, 2002; Maeda K, 2013).

Rasa nyeri saat persalinan merupakan hal yang normal terjadi, penyebabnya meliputi faktor fisiologis dan psikologis, faktor fisiologis yang dimaksud adalah kontraksi, gerakan otot-otot rahim memanjang dan kemudian memendek. Serviks juga akan melunak, menipis dan mendatar, kemudian tertarik, saat itulah kepala janin menekan mulut rahim dan membukanya, jadi intensitas nyeri dari awal pembukaan sampai pembukaan lengkap akan meningkatnya nyeri dan semakin sering. Penelitian telah menunjukkan nyeri yang muncul saat kala I persalinan terutama dimediasi akibat distensi mekanik segmen bawah rahim ditambah dengan dilatasi serviks dan kontraksi ototnya sendiri kontraksi uterus menyebabkan regangan dan trauma sehingga terjadi rangsangan saraf aferen (Cunningham, 2013; Maeda K, 2013; Selman T, 2010, Shnol H, 2014; Zhang J, 2010). Faktor psikologis yang dapat meningkatkan rasa nyeri adalah rasa takut dan cemas yang berlebihan akan memengaruhi rasa nyeri. Situasi dan kondisi psikologis yang labil memegang peranan penting dalam memunculkan nyeri persalinan yang lebih berat. Salah satu mekanisme pertahanan jiwa terhadap stres adalah konversi yaitu memunculkan gangguan secara psikis menjadi gangguan fisik (Andarmoyo S, 2013; Kashanian M, 2010).

Pemberian terapi akupunktur pada titik LI-4 dan SP-6 dapat menghambat peningkatan nyeri persalinan seiring dengan penambahan pembukaan dan peningkatan his ibu karena stimulasi akupunktur pada titik LI4 dan SP-6 melalui hambatan nosiseptif pada tingkat presinaptik pada kornu bagian dorsal, sehingga menghambat transmisi ke sentral. Rangsangan akupunktur mengaktifasi ambang rendah serabut syaraf bermielin. Infut aferen dari serabut ini menghambat propagasi nosiseptif yang dibawa oleh serabut-serabut $\mathrm{C}$ kecil tidak bermielin dengan menghambat transmisi sepanjang serabut saraf ini ketarget sel $\mathrm{T}$ yang terdapat pada substansia gelatinosa kornu dorsal. 
Mekanisme analgesi yang dihasilkan oleh akupunktur dapat dijelaskan dengan teori pengontrolan gerbang (Gate Control Theory). Teori ini menjelaskan bahwa serabut saraf dengan diameter kecil yang membawa stimulus nyeri akan melalui pintu yang sama dengan serabut yang memiliki diameter lebih besar yang membawa impuls raba mekanoreseptor, apabila kedua serabut saraf tersebut secara bersama-sama melewati pintu yang lebih kecil. Gerbang biasanya tertutup, menghalangi secara konstan transmisi nosiseptive melalui serabut $\mathrm{C}$ mencapai ke sel $\mathrm{T}$, jika timbul rangsangan nyeri perifer, informasi dibawa oleh serabut $\mathrm{C}$ mencapai ke sel $\mathrm{T}$ dan gerbang akan terbuka, menyebabkan transmisi sentral ke thalamus dan korteks dimana impuls akan diinterpretasikan sebagai nyeri (Anderson D, 2011; Yu J-S, 2013).

Penelitian Qu F dan Zhou J di Cina (2006) menyimpulkan bahwa stimulus pada titik Large Intestinal (LI-4) dan Spleen 6 (SP6 ) dapat meningkatkan kadar $\beta$-endorfin ( $\beta$ EP) dan serotonin (5-HT) dalam darah yang dapat menurunkan nyeri persalinan dan meningkatkan relaksasi (Qu F, 2006)

Stimulasi akupunktur pada titik LI-4 mengakibatkan endogen, jalur antinociceptive di hipotalamus dan otak tengah karena peningkatan endorphinergic di hipotalamus, neuron endorphinergic ini turun ke PAG dan raphe nuchleus sehingga menghambat rangsangan nyeri. Jalur serotonin(5-HT) menghubungkan sumsum tulang belakang dari batang otak yang memainkan peran penting suasana hati dan emosi, serotonin dilepaskan dari nucleus accumbens (Saputra K, 2009; Asadi N, 2015; Yu J-S, 2013). Penelitian elektro akupunktur pada titik LI-4 secara signifikan dapat meningkatkan kadar prostaglandin E2 (PGE2) dalam uterus dan serviks, Estradiol (E2) dan Progesteron (P) dalam cairan ketuban. Elektro akupunktur pada titik SP-6 secara signifikan dapat meningkatkan kadar Progesteron (P) dalam cairan ketuban (Mei-Qin W, 2003)

Akupunktur pada titik LI-4 dan SP-6 mengeluarkan $\beta$-endorfin dan serotonin yang dapat menghambat rangsangan nyeri. ${ }^{11,}$ 21-26
Penggunaan terapi akupunktur tidak dapat menghilangkan nyeri secara keseluruhan, tetapi terapi akupunktur dapat menghambat nyeri persalinan ketika terjadi penambahan pembukaan sekviks dan peningkatan kontraksi rahim. Titik akupunktur merupakan zone of autonomic concentration yang mempunyai hubungan dengan organ dalam, sehingga rangsangan pada zona ini akan memengaruhi fungsi organ yang bersangkutan. Rangsangan pada zona ini akan berjalan secara segmental ke medula spinalis, sehingga pada akhirnya dapat mempengaruhi serabut saraf simpatis maupun parasimpatis. Serabut saraf simpatis keluar dari medula spinalis pada segmen torakolumbal, sedangkan serabut saraf parasimpatis keluar dari kranial melalui saraf kranial III, VII, IX dan X serta keluar dari medula spinalis pada segmen sakral, sehingga titik ini dapat menghambat nyeri persalinan.

\section{KESIMPULAN}

Terapi akupunktur pada titik LI-4 dan SP-6 dapat menghambat peningkatan nyeri persalinan kala I fase aktif dibandingkan dengan kelompok $\mathrm{K}$.

\section{SARAN}

Pengembangan penelitian selanjutnya dengan menggunakan titik akupunktur LI-4 dan SP-6 dilihat dari pemeriksaan kadar $\beta$ endorfin yang dapat digunakan sebagai terapi alternatif untuk menghambar nyeri persalinan.

\section{DAFTAR PUSTAKA}

Akbarzadeh M, Masoudi Z, Hadianfard MJ, Kasraeian M, Zare N. Comparison of The Effects of Maternal Supportive Care and Acupressure (BL32 Acupoint) on Pregnant Women's Pain Intensity and Delivery Outcome. Hindawi Publishing Corporation Evidence-Based Complementary and Alternative Medicine. 2014;2014:7.

Anderson D. A review of systemic opioids 
commonly used for labor pain relief. Journal of Midwifery \& Women's Health. 2011;56(3):222-39.

Andarmoyo S, Suharti. Persalinan Tanpa Nyeri Berlebihan. Yogyakarta: Ar-Ruzz Media; 2013.

Asadi N, Maharlouei N, Khalili A, Darabi Y, Davoodi S, Raeisi Shahraki H, et al. Effects of LI-4 and SP-6 Acupuncture on Labor Pain, Cortisol Level and Duration of Labor. Journal of acupuncture and meridian studies. 2015;8(5):249-54.

Burham. Pedoman Praktis Safe Motherhood. Perawatan Dalam Kelahiran Normal. Jakarta: EGC; 2003.

Cunningham, Levono, Bloom, Hauth, Rause, Spong. Obstetri Williams. 23 ed. Jakarta: EGC. Penerbit Buku Kedokteran; 2013.

Chapman V, Cathy C. The Midwife's Labour And Birth Handbook. 3 ed: WileyBlackwell; 2013.

Fyneface-Ogan S, Gogo Job O, Enyindah C. Comparative effects of single shot intrathecal bupivacaine with dexmedetomidine and bupivacaine with fentanyl on labor outcome. ISRN Anesthesiology. 2012;2012.

Gizzo S, Di Gangi S, Saccardi C, Patrelli TS, Paccagnella G, Sansone L, et al. Epidural analgesia during labor: impact on delivery outcome, neonatal wellbeing, and early breastfeeding. Breastfeeding Medicine. 2012;7(4):2628.

Harper TC, Coeytaux RR, Chen W, Campbell K, Kaufman JS, Moise KJ, et al. A randomized controlled trial of acupuncture for initiation of labor in nulliparous women. The journal of maternal-fetal \& neonatal medicine : the official journal of the European Association of Perinatal Medicine, the Federation of Asia and Oceania Perinatal Societies, the International Society of Perinatal Obstet. 2006;19(8):465-70.

Kashanian M, Shahali S. Effects of acupressure at the Sanyinjiao point (SP6) on the process of active phase of labor in nulliparas women. The Journal of Maternal-Fetal \& Neonatal Medicine. 2010;23(7):638-41.

Kiswojo. Akupunktur Medik. Jakarta: Akupunktur Indonesia; 2013.

Lowe NK. The nature of labor pain. American journal of obstetrics and gynecology. 2002;186(5):S16-S24.

Liang F, Chen R, Cooper EL. Editorial NeuroendocrineMechanisms of Acupuncture. Hindawi Publishing Corporation Evidence-Based Complementary and Alternative Medicine. 2012;2012:1-2.

Maeda K. Uterine contractions in normal labor developed by a positive feed-back and oscillation. Journal of Health \& Medical Informatics. 2013;2013.

Ma W, Bai W, Lin C, Zhou P, Xia L, Zhao C, et al. Effects of Sanyinjiao (SP6) with electroacupuncture on labour pain in women during labour. Complementary Therapies in Medicine. 2011;19, Supplement 1:S13-S8.

Mei-Qin W, Jiang Z, Lu-Fen H. Experimental study on the mechanism of electroacupuncture at LI 4 and SP 6 points for promoting labor. Chinese Acupuncture \& Moxibustion. 2003;23:593-6.

Mucuk S, Baser M. Effects of noninvasive electroacupuncture on labour pain and duration. Journal of clinical nursing. 2014;23(11-12):1603-10.

Ma W, Zhou P, Zhang Y, Yuan Y, Wu Y, Zhao $\mathrm{C}$, et al. [Clinical observation on the effect of electroacupuncture of Sanyinjiao (SP 6) on labor]. Zhen ci yan jiu= Acupuncture research/[Zhongguo yi xue ke xue yuan Yi xue qing bao yan jiu suo bian ji]. 2010;35(3):217-21.

$\mathrm{Qu}$ F, Zhou J. Electro-Acupuncture in Relieving Labor Pain2006; 4(1):[12530 pp.].

Selman T, Johnston T. Mechanisms and management of normal labour. Obstetrics, Gynaecology \& 
Reproductive

Medicine.

2010;20(7):201-6.

Shnol H, Paul N, Belfer I. Labor pain mechanisms.

International

anesthesiology clinics. 2014;52(3):1-17.

Saputra K, Sudirman S. Akupunktur Untuk Nyeri Dengan Pendekatan Neurosain. 1 ed. Jakarta: Sagung Seto; 2009.

Smith CA, Collins CT, Crowther CA, Levett KM. Acupuncture or acupressure for pain management in labour. Cochrane Database Syst Rev. 2011;7.

Wignyomartono SS. Akupunktur Untuk Nyeri Persalinan Bebas Nyeri. 2 ed. Surakarta: UNS Press; 2012.

Xiang XC, Zhang P. How Acupuncture works? Neuroscientific basis underlying Acupuncture Analgesia:[1-19 pp.].

$\mathrm{Yu}$ J-S, Zeng B-Y, Hsieh C-L. Acupuncture stimulation and neuroendocrine regulation. Int Rev Neurobiol. 2013;111(125-140).

Zhang J, Troendle J, Mikolajczyk R, Sundaram R, Beaver J, Fraser W. The natural history of the normal first stage of labor. Obstetrics \& Gynecology. 2010;115(4):705-10. 